\title{
RELATIONSHIP BETWEEN GENDER OF SCHOOL-GOING ADOLESCENTS AND ALCOHOL CONSUMPTION IN ILORIN, NIGERIA
}

\author{
David Obafemi Adebayo ${ }^{1}$, Mohd Tajudin Ninggal ${ }^{2}$, Alfred Akinbo Adegoke ${ }^{1}$ \\ 1 Department of Counsellor Education, Faculty of Education, University of Ilorin, Nigeria. \\ ${ }^{2}$ Department of Educational Foundations, School of Education, Universiti Teknologi Malaysia. \\ *Corresponding Author Email : yomieva@gmail.com; tajma28@utm.my ;fredgoke2@yahoo.com
}

This is an open access article distributed under the Creative Commons Attribution License, which permits unrestricted use, distribution, and reproduction in any medium, provided the original work is properly cited

\section{ARTICLE DETAILS}

\section{Article History:}

Received 26 June 2018 Accepted 2 July 2018

Available online 1 August 2018

\section{ABSTRACT}

Alcohol use among school-going adolescents has reached levels that give practitioners in the helping, teaching and health professions serious concerns. This study focused on the relationship between gender of school-going adolescents and alcohol consumption in Ilorin, Nigeria. Survey design was adopted. 300 respondents were randomly selected for the study, having purposively picked 10 secondary schools. One hypothesis was tested at 0.05 alpha level of significance. Data collected were analyzed using descriptive and inferential statistics. Results revealed that gender has no significant relationship on school-going adolescents' consumption of alcohol. The study concluded that adolescents of school-going ages indulge in alcohol consumption equally irrespective of gender. It was recommended that promulgation of effective laws that could restrict sales and consumption of alcoholic drinks to youths of school-going ages would be an effective strategy for reducing school-going adolescents' heavy alcohol consumption in Ilorin, Nigeria

\section{KEYWORDS}

Alcohol, Consumption, Gender, Binge drinking, School-going adolescents.

\section{INTRODUCTION}

Adolescence is the age period during which alcohol and drug use are typically initiated and experimented by youngsters. This is probably true because of the different bodily changes they experience at this stage of life [1]. A group researchers indicated that $51 \%$ adolescents tried alcohol at 8th grade (equivalent of JSS2- Lower Basic in Nigeria), 80.3\% in 12th grade (equivalent of SSS3- Upper Basic in Nigeria) [2]. Heavy episodic drinking (also known as binge drinking), defined as five or more drinks in one episode. This, the researchers, reported that over $30 \%$ of 12 th-graders are involved (SSS3 - Upper Basic). These statistics have been stable for several years, indicating that alcohol experimentation is normative and binge drinking common among adolescents. However, because adolescent drinking is developmentally normative does not mean that it is without clinical or public health implications. Alcohol remains the most widely used substance among adolescents and studies revealed that the proportion of youth who use alcohol increases during adolescence [3]. In the Nigerian society, alcohol use occurs as a means of strengthening the bond of friendship or kinship. It is also used during worship of ancestral gods and during marriage or funeral ceremonies [4].

Alcohol is produced when grains, fruits or vegetables are fermented. Fermentation is a process that uses yeast or bacteria to change the sugars in the food into alcohol. Fermentation is used to produce many essential items ranging from cheese to medications. Alcohol has different forms, and it can be used as a cleaner, an antiseptic or a sedative.

The question therefore is, if alcohol is a natural product, as on the surface, why should school-going adolescents be of concern in relation to the consumption? The effects of alcohol in human system is summarized thus; when alcohol is taken (drunk), it is absorbed into the blood stream and from there, it spreads through the Central Nervous System (CNS), the brain and the spinal cord which controls almost all body functions. The outcome of this includes mal-adaptive behaviors, recklessness as well as relaxed muscles.

There are two classes of alcoholic beverages, they are: Natural fermentation beverages and distilled beverages [5]. According to the author, wines and beers are in the class of natural fermentation beverages and are produced through the action of yeast on sugar contained in cereals, grains and fruits with other chemicals added in some cases for colouration and flavoring. Natural fermentation stops at $14 \%$ alcohol level; therefore, a normal fermented alcohol cannot contain more than $14 \%$ alcohol level. Examples of most common natural fermentation beverages (wines and beers) in Nigeria includes: Trophy, Star, Gulder, Harp and Bacchus tonic wine.

Distilled beverages on the other hand are wines and beers subjected to other processes to increase their alcoholic content by heating them to the boiling point and evaporating and then collecting them into a reservoir where they turn back into liquid form. The end product is distilled spirits, like Whisky, Gin, Ogogoro and Schnapps [5]. Generally, natural fermentation and distilled beverages are regarded as food since they fill the stomach and do not make one feel hungry. Indeed, the consumption of these beverages (wines and beers) categorized as naturally fermented beverages is on the premise that they contain some nutritious elements like vitamins and minerals and may not be as intoxicating as those categorized as distilled spirits. This assumption however, is never a justification for consumption among school-going adolescents given the assumed uncontrollable dimension of its in-take asides that of traditional use. 
This uncontrolled alcohol intake, according to findings may lead to occurrence of some adverse effects on the liver, bone, growth, and endocrine development. Some of the identified symptoms for both male and female school-going adolescents and teens that have been heavy alcohol users include, though not limited to the following: perspiring, agitation, brief seizures, tremors and disorientation [6].

Available submissions from literature revealed that several factors account for indulgence of teenagers, particularly girls in heavy alcohol consumption, some of which include; parental indulgence in alcohol, peergroup influence; desire for recognition, clubbing, early exposure to media excesses, societal influence, and experimenting with alcoholic drinks. Hence, the focus of this study.

Specifically, this study was concerned with refuting or affirming studies on gender differences in alcohol use among adolescents that have consistently shown that males consume alcohol more frequently and in higher quantities than females and are prone to experience more alcoholrelated problems $[7,8]$. As a guide, only one hypothesis was formulated and put to test in this study.

\subsection{Objective}

The study is aimed at determining the relationship between gender of school-going adolescents and alcohol consumption in Ilorin metropolis, Nigeria.

\subsection{Hypothesis}

Ho1: there is no significant relationship in alcohol consumption among school-going adolescents on the basis of gender.

\section{METHODOLOGY}

The study being a quantitative type, adopted survey design, with purposive sampling technique used to draw samples from 10 public and private secondary schools in Ilorin metropolis, Kwara State, Nigeria [912]. The data in this study were primary data, being responses elicited from 300 respondents who participated in the study.

\subsection{Demographic Data Description}

Table 1 shows the distribution of respondents on the basis of gender and reveals that out of 300 respondents, 156 representing $52 \%$ of the total respondents were males while 144 representing $40 \%$ were females.

Table 1: Frequency Distribution of Respondents based on Gender

\begin{tabular}{cll}
\hline Gender & Frequency & Percentage (\%) \\
\hline Male & 156 & 52.0 \\
Female & 144 & 48.0 \\
Total & 300 & 100 \\
\hline
\end{tabular}

\subsection{Hypothesis Testing}

Table 2 reveals that the calculated $t$-value of 0.12 was less than the critical $\mathrm{t}$-value of 1.96. This implies that gender has no significant difference on school-going adolescents' consumption of alcohol in Ilorin metropolis
[13]. The formulated hypothesis which states that there is no significant relationship in alcohol consumption among school-going adolescents on the basis of gender is therefore retained.

Table 2: t-test Analysis showing the difference in the alcohol consumption among school-going adolescents on the basis of gender

\begin{tabular}{|c|c|c|c|c|c|c|c|}
\hline Gender & $\mathbf{N}$ & Mean & SD & df & Cal t-val & Crit. t-val & Sig. \\
\hline Male & 156 & 103.365 & 13.08 & \multirow{3}{*}{298} & \multirow{3}{*}{0.12} & \multirow{3}{*}{1.96} & \multirow{3}{*}{0.08} \\
\hline & & & & & & & \\
\hline Female & 144 & 103.648 & 13.353 & & & & \\
\hline
\end{tabular}

\section{CONCLUSION AND RECOMMENDATIONS}

The major finding of this study based on the tested hypothesis is that gender has no significant relationship on school-going adolescents' consumption of alcohol. This implies that adolescents of school-going age indulge in alcohol consumption equally irrespective of gender. This is consistent with youngsters of both sexes, between ages $15-30$ were heavily involved in alcohol consumption. It follows however that males and females alike do not differ in their alcohol consumption.

Studies carried out confirmed youngsters of school ages have been identified as a major group involved in heavy consumption of alcoholic drinks of all types. This according to the authors have been going on for more than ten years nonstop. Their study found that there was high prevalence of alcohol use among male and female students of tertiary institutions in Nigeria's South-Eastern states. This however contradicts the view that male students are more inclined to drugs and alcohol addiction than their female counterparts. The researcher explained further that certain factors prompt some boys (though in girls, but not well pronounced) to indulge in alcohol and drug use generally. Those factors according to the researcher include desire for boldness to face a crowd, better performance on sporting activities or events, boldness adequate enough to confront the opposite sex or any other challenging situation.

Given the prevalence and the attendant dangerous effects of alcohol consumption among school-going adolescents which have been severally established by previous researchers, as well as the findings emanating from this study, it is therefore recommended that timely promulgation of effective policies and laws that can restrict the sales and consumption of alcoholic drinks to adolescents of school-going ages be enforced by appropriate government agencies. This, in the view of the researchers, may go a long way in saving the future of the teeming school-going adolescents from the predictive mental and medical destructive potentials of indiscriminate use of alcoholic drinks. It is also hoped that adequate guidance and counselling measures will be put in place to provide proper drug and alcohol education to the youngsters. This agrees with youngsters should be adequately informed and guided on alcohol use in order to avoid the serious health and societal consequences its continuous use or consumption poses.

\section{REFERENCES}

[1] Adegoke, A.A. 2013. Drugs and Alcohol among Youths. GNS 211 Textbook. University of Ilorin Press.

[2] Johnston, P.B., O'Malley, P.M., Bachman, J.G. 2001. Monitoring the future: National results on adolescent drug use. Bethesda, MD: National Institute on Drug Abuse.

[3] Duncan, S.C., Duncan, T.E., Strycker, L.A. 2006. Alcohol use from ages 916: A cohort sequential latent growth model. Drug and Alcohol Dependency, 81, 71-81.

[4] Adebayo, D.O. 2012. Factors Influencing Alcohol-use among Schoolgoing adolescent in Ilorin metropolis. Unpublished undergraduate project, Department of Counsellor Education, University of Ilorin.

[5] Moronkola, O.A. 1996. Social Effects of Alcohol Use and Abuse. Nigerian Journal of Clinical and Counselling Psychology.

[6] Eloe, K., Mariana, S. 2007. Alcohol Use among College Students. An International Perspective. Lippincolt.

[7] Barnes, G.M., Welte, J.W. 1986. Patterns and predictors of alcohol use among 7-12th graders in New York State. Journal of Studies on Alcohol, $47,53-62$. 
[8] Thomas, B.S. 1996. A path analysis of gender differences in adolescent onset of alcohol, tobacco and other drug use (ATOD), reported ATOD use and adverse consequences of ATOD use. Journal of Addictive Disease, 15, 33-52.

[9] Ebirim, C., Morakinyo, O.M. 2009. Prevalence and Perceived Health Effect of Alcohol Use Among Male Undergraduate in Owerri, South-East, Nigeria.

[10] Adekunjo, R.O. 2017. Perception of youths in Egbe towards health implications of alcohol consumption. Unpublished Nursing Research project. ECWA School of Nursing, Egbe, Kogi State, Nigeria.

[11] Ajayi, 0.0. 2013. Causes and consequences of drug use among inschool adolescents in Ilorin metropolis. Unpublished undergraduate project, Department of Counsellor Education, University of Ilorin, Nigeria.

[12] Dennis, C., Jon, D. 2010. Alcohol and Drug Use.

[13] Saturday Tribune Newspaper of April 30, 2011. Healthy Heart with Dr. B. Adeoye.

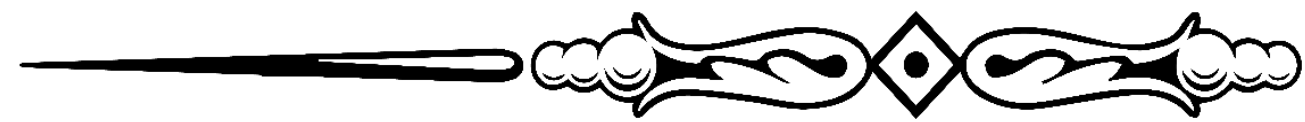

